\title{
TERRITORIALLY-ORIENTED MODEL OF MANAGEMENT OF PROCESSING ENTERPRISES OF UKRAINE
}

\author{
Nadezhda ONIKIENKO' \\ Kherson National Technical University, Ukraine
}

\begin{abstract}
The subject of research of this article are the processing enterprises of Ukraine. In the period of political and economic instability, when state decentralization is carried out and territorial communities receive greater powers and resources, the issue of building a model of enterprise management is becoming increasingly important. The purpose of the article is to develop an effective model for managing processing enterprises in the relevant direction of the development of the state. Methodology. During the analysis it was established that an effective management model for processing enterprises should be consistent with the development strategies of the state and a particular region. These strategies are interrelated and provide for a comprehensive system approach. The study is based on an analysis of the strengths and weaknesses of the region: geographic, economic, industrial. Based on the analysis of the strengths of the region, the opportunities for efficient development of processing enterprises in the given territory were determined and a model of territorially-oriented management of enterprises was developed. The model is based on the principles of economic and political development of the region, with the help of which, its opportunities are realized. Conclusions. Territorial-oriented management of a processing enterprise is an effective model of organization and management. This model covers all spheres of influence on the development of the enterprise. It is based on the interrelation of the territory and the processing enterprise and ensures the receipt of state support within the framework of the approved development strategy for a certain territory. In the proposed model, we observe that at the first stage - the organization of the enterprise, its founder is guided by the geographically attractive location of the enterprise. At the second stage-development, the enterprise developing in accordance with the strategies of development of regions and the state, has the opportunity to receive state support and positively affect the territory, reducing its negative sides, developing it.
\end{abstract}

Key words: processing enterprises, geographically-oriented model, effective management, industrial potential, foreign economic relations.

JEL Classification: M21, M29, M11, M20, F42

\section{1. Вступмение}

На Аанном историческом этапе развития экономика Украины трансформируется, вектор развития экономических отношений стремится к европейскому. ПереА государственной властью на каждом уровне стоит задача - сохранить стабильность и обеспечить Аальнейшее экономическое развитие регионов и государства. ОАним из основных направмений развития Украины явмяется расширение и упрощение доступа украинских товаров на рынки государств - членов Европейского Союза. Аля осуществления Аанной цели необходимо приведение системы технического регумирования в соответствие с европейскими требованиями и завершения реформирования системы государственного контромя наА безопасностью и качеством пищевых продуктов. Важная роль в Аанном направлении развития экономики и промышленности Украины принаАлежит перерабатывающим преАприятиям.
Проблематика эффективного управления перерабатывающими предприятиями нашиа свое отражение в работах многих украинских исследователей, среди которых Базилевич В. А., Белорус О.Г., Боринец С.Я., Гамьчинский А.С., Ещенко П.С., Пешко А.В., Рязанова Н.С. и Аругие. Среди зарубежных ученых, разрабатывающих Аанную тематику, следует отметить $\Lambda$. Бальцеровича, Т. ЭАисона, А. Зиденберга, Т. Килликом и Ар. ОАнако, несмотря на значительный объем научных Аостижений в этой сфере, некоторые вопросы разработки эффективной модели управления перерабатывающими предприятиями и ее влияние на регион размещения преАприятий имеют противоречивый и Аискуссионный характер.

В периоА политической и экономической нестабильности, когАа осуществляется государственная Аецентрализация и территориальные общины получают большие полномочия и ресурсы - вопрос построения модеми управления преАприятиями при-

Corresponding author:

${ }^{1}$ Department of Finance, Banking and Insurance, Kherson National Technical University.

E-mail: nfemerald@ukr.net 
обретает все большую актуальность. Таким образом, научная новизна статьи заключается в разработке эффективной модеми управления перерабатывающими преАприятиями.

Целью статьи является разработка модели управмения перерабатывающими преАприятиями соответствующей целевому направлению развития государства. Модель основывается на основных принципах экономического и политического развития региона, с помощью которой реализуются его возможности на основании сильных сторон территории.

\section{2. Стратегия устойчивого развития Украины и ее регионов}

Аля экономического развития Украины и регионов Президентом Украины быи подписан Указ «О стратегии устойчивого развития «Украина-2020» (Decree of the President 2015). Эта стратегия опредемяет основные векторы развития экономики, политического устройства, основы деятельности производства. Стратегия устойчивого развития предполагает реализацию реформ и программ по направлениям: развитию, безопасности, ответственности, гордости. И одной из первоочередных задачи явмяется реализация программы дерегумяции и развитию преАпринимательства.

Согласно Стратегии устойчивого развития « Украина-2020» была разработана и утверждена Стратегия развития Херсонской области на периоА Ао 2020 года (Strategy for the development of the Kherson region 2015), которая предусматривает ускорение темпов развития региона, повышение ее конкурентных позиций.

Стратегия предусматривает развитие территории Херсонской области с соблюдением международных стандартов сохранения и развития окружающей среды. Основывается на принципах ресурсосбережения, с учетом действующей системы расселения по принципу ее сохранения и развития. Осуществмяется приоритетное развитие точек экономического роста, обеспечивающих равномерное продвижение территории области с учетом традиционных направмений экономики и возможности развития отраслей, которые органично сочетаются с уже Аействующими Производствами и АоПолняют их.

Реализация Стратегии развития Херсонской области предусматривает формирование комплексной системы проектов, выполнение которых базируется на осуществлении влияния кажАого проекта как на общую ситуацию в Херсонской области, так и на ситуацию на уровне территориальных общин. Определяющее место в разработке и внеАрении мероприятий Стратегии развития предоставляется именно территориальным общинам, веАь она разрабатывается на основе преАставменных ими проектов.
А^я развития перерабатывающих предприятий в рамках Стратегии развития Херсонской области определены следующие стратегические цели: обеспечение условий Аля развития перерабатывающей промышленности, содействие развитию сертификационного центра Аля сельскохозяйственных преАприятий, содействие созАанию и развитию семейных фермерских хозяйств, финансовая подАержка мероприятий в агропромышленном комплексе путем удешевления кредитов. То есть, по нашему мнению, основными задачами Амя развития перерабатывающих преАприятий явмяются: умучшение инвестиционного климата, повышение уровня сертификации и стандартизации качества продукции и обеспечения экологических норм продуктов переработки, использования инструментов бюАжетного обеспечения ААя осуществмения указанных цемей.

\section{3. Анализ потенциала региона}

Аля построения модели госуАарственной поААержки перерабатывающих преАприятий, проанализируем симьные и слабые стороны региона.

Симьные стороны Херсонской области предкагаем условно разделить на территориально-географические, промышиенные и экономические.

К сильным территориально-географическим сторонам, на наш взгляА, относятся:

- выход области в черноморско-азовского побережье. По территории области проходит госуАарственная граница протяженностью 458 км, в том числе по морям: Черному - 350 км, Азовском - 108 км. Это явмяется возможностью ААя развития транспортной инфраструктуры, туризма, а также активного участия в трансграничном сотрудничестве стран Черноморского бассейна;

- значительный транспортный потенциал. Присутствуют и развиваются все основные виды транспорта. Инфраструктура области включает автомобильный, жемезнодорожный, водный и воздушный транспорт. Функционирует аэропорт с межАународным статусом. Благодаря этому возможные внутригосударственные и внешнегосударственные экономические связи;

- многообразие природных ресурсов, созАает необходимые условия Аля развития хозяйственной Аеятельности. Имеющиеся земельные и значительные водные ресурсы, в том числе свободные Аля использования в зоне рекреации; высококачественные южные черноземы; искусственные месные массивы общей площадью 130,7 тыс. га; полезные ископаемые: известняк, глинистые породы, камни, минеральные воды, соли,

- значительный потенциал Аля развития нетрадиционной и возобновмяемой энергетики. Часть области имеет равнинный рельеф в солончаковых степях, благоприятный Аля строительства ветро- и солнечных элек- 
тростанций. Количество солнечных Аней и скорость ветра обеспечивают высокую рентабельность объектам нетрадиционной энергетики. Это явмяется важным фактором развития перерабатывающих предприятий на территории области, так как способствует удешевлению себестоимости произвеАенной продукции.

- значительный агропромышленный потенциал, сельскохозяйственный кластер. В структуре земель сельскохозяйственного назначения 49,9\% составмяют черноземы (южные и обыкновенные). Имеющиеся 426,8 гектаров орошаемых земель, предприятий по производству и ремонту сельскохозяйственной техники и оборудования Аля капемьного орошения, мощного трудового потенциала (39\% трудоспособного населения - жители сельской местности). Равнина сельскохозяйственных земель благоприятна Аля ведения крупнотоварного производства. Наличие 69 преАприятий по переработке сельскохозяйственной проАукции и произвоАства пищевых проАуктов и напитков, которые имеют хорошую репутацию Аалеко за предеками Украины;

- обеспеченность трудовыми ресурсами на Аанном этапе развития экономики, потенциал Аһя поАГотовки и переподготовки каАров. 65\% населения в трудоспособном возрасте явмяется экономически активным, значительная часть населения имеет высшее образование. В области функционируют 26 высших учебных заведений, из них 9 - III-IV уровней аккредитации и 26 государственных профессионально-технических учебных заведений;

- высокий интемлектуальный потенциал в сфере АПК. Наличие высоких техномогий в области переработки, которые могут быть использованы как площаАки Аля распространения технологий. Имеющиеся научные школы, учрежАения сельского хозяйства. Сложившаяся Аобра сортовая база, активно внеАряются высокие технологии в перерабатывающее производство.

Экономическим потенциалом области явцяются:

- наличие значительного количества земельных участков, пригодных Аля введения инвестиционной Аеятельности на территории области. Существует 220 земельных участков общей площадью 8432,52 гектаров преимущественно семьскохозяйственного назначения;

- экспортоориентированная специфика внешнеторговой Аеятемьности;

- гибкость рынков урбанизированных территорий области за значительный преАпринимательский потенциам (141 человек, занята в преАпринимательстве, на 1000 человек насемения).
Исходя из анализа сильных сторон области, можем определить возможности Аля эффективного развития перерабатывающих предприятий на территории Аанного региона (рис. 1, 2, 3).

Так, благодаря выгодному территориально-географическому положению Херсонской области, по нашему мнению, открываются перспективы и возможности Аля перерабатывающих преАприятий в Аанном регионе. Такое размещение перерабатывающих преАприятий способствует быстрой Аоставке продуктов переработки к заказчикам, а также способствует развитию и укреплению внешнеэкономических связей перерабатывающих предприятий, благодаря чему они развиваются и имеют положительный экономический эффект.

ОАной из возможностей явмяется УАобство Аоставки материалов, так как область имеет выхоА К Авум морям и значительный транспортный потенциам.

Такое размещение перерабатывающих предприятий способствует быстрой Аоставке продуктов переработки к заказчикам, а также способствует развитию и укреплению внешнеэкономических связей перерабатывающих предприятий, благодаря чему перерабатывающие предприятия развиваются и имеют положительный экономический эффект.

Обкасть имеет значитемьный потенциа Аля развития нетрадиционной воспроизведенной энергетики, что может способствовать высвобожАению среАств Аля улучшения инвестиционного кмимата, проведе-

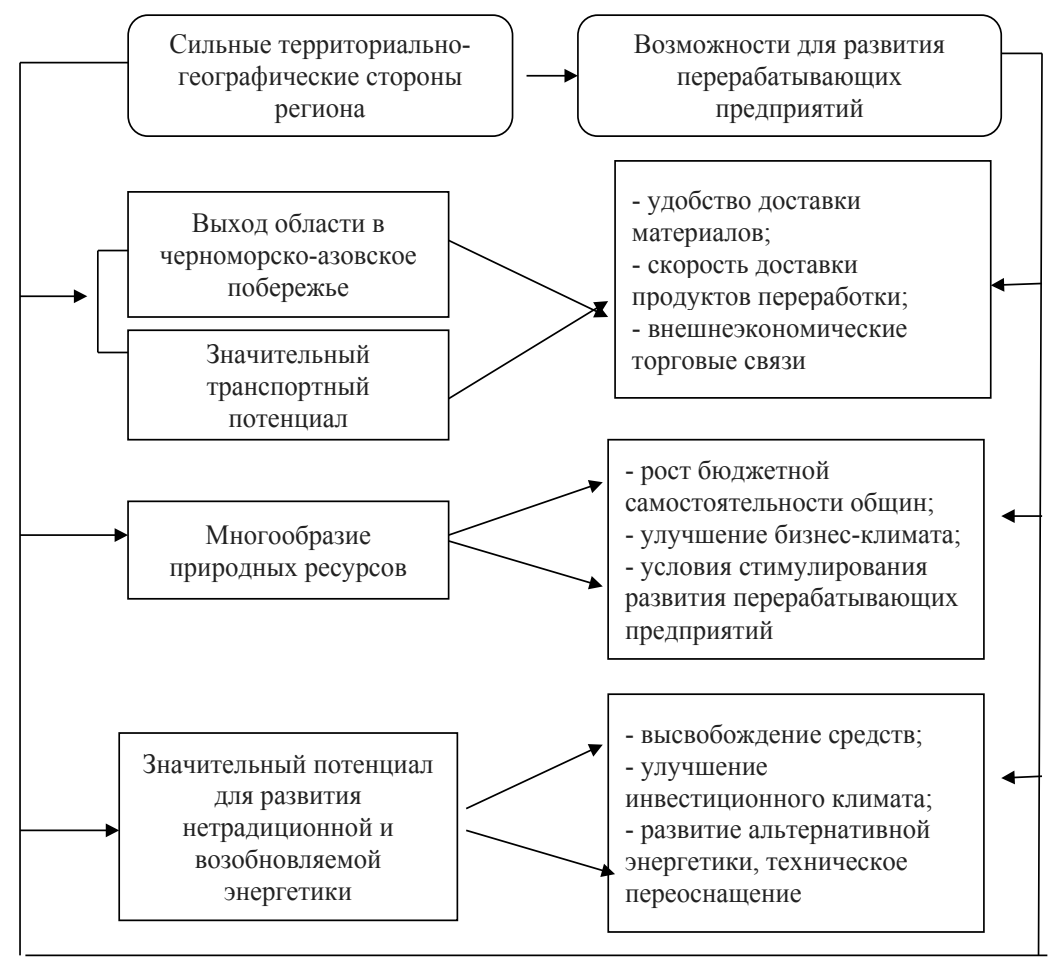

Рис. 1. Возможности Аля развития перерабатывающих преАприятий благодаря территориально-географическому поможению региона

Источник: разработано автором 


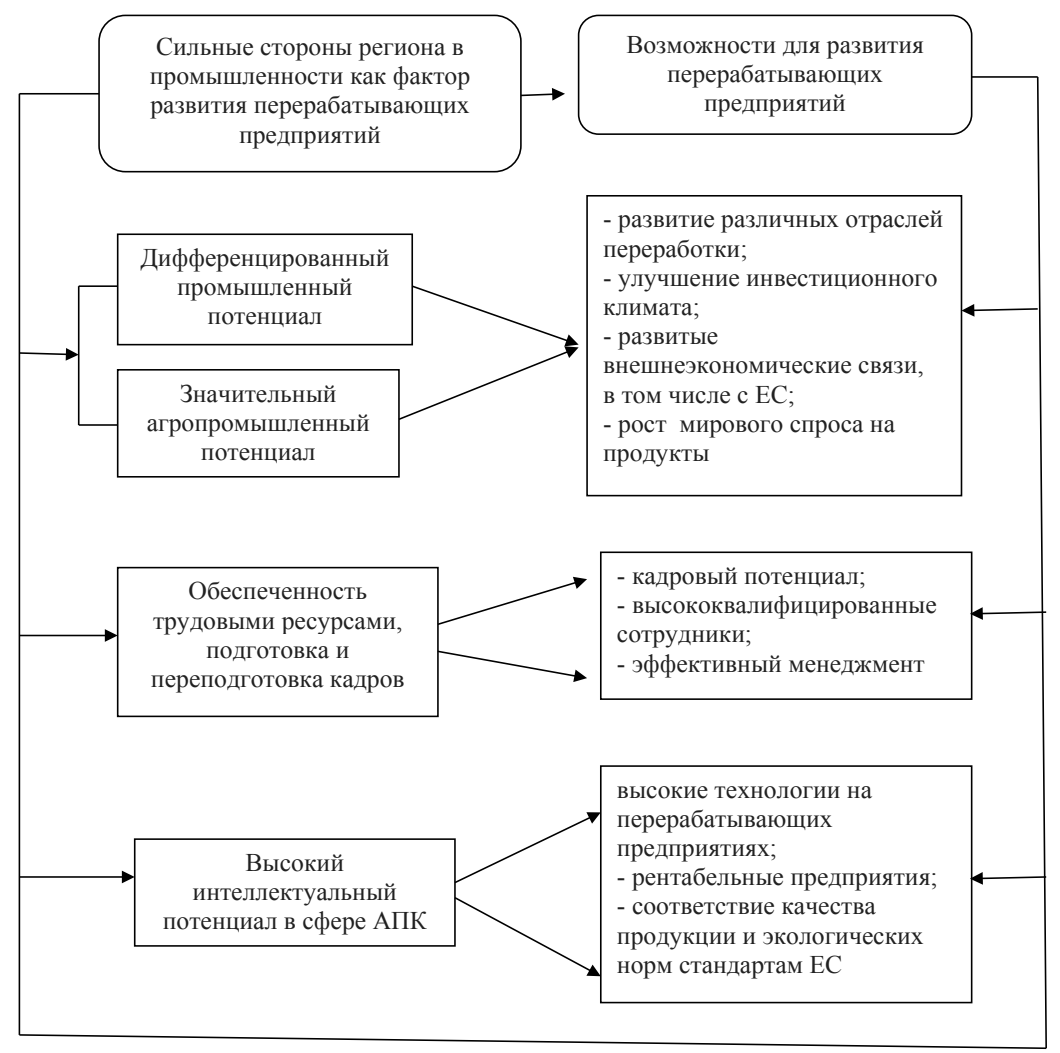

Рис. 2. Возможности Амя развития перерабатывающих преАприятий бцагодаря симьным сторонам региона в промышиенности

Источник: разработано автором

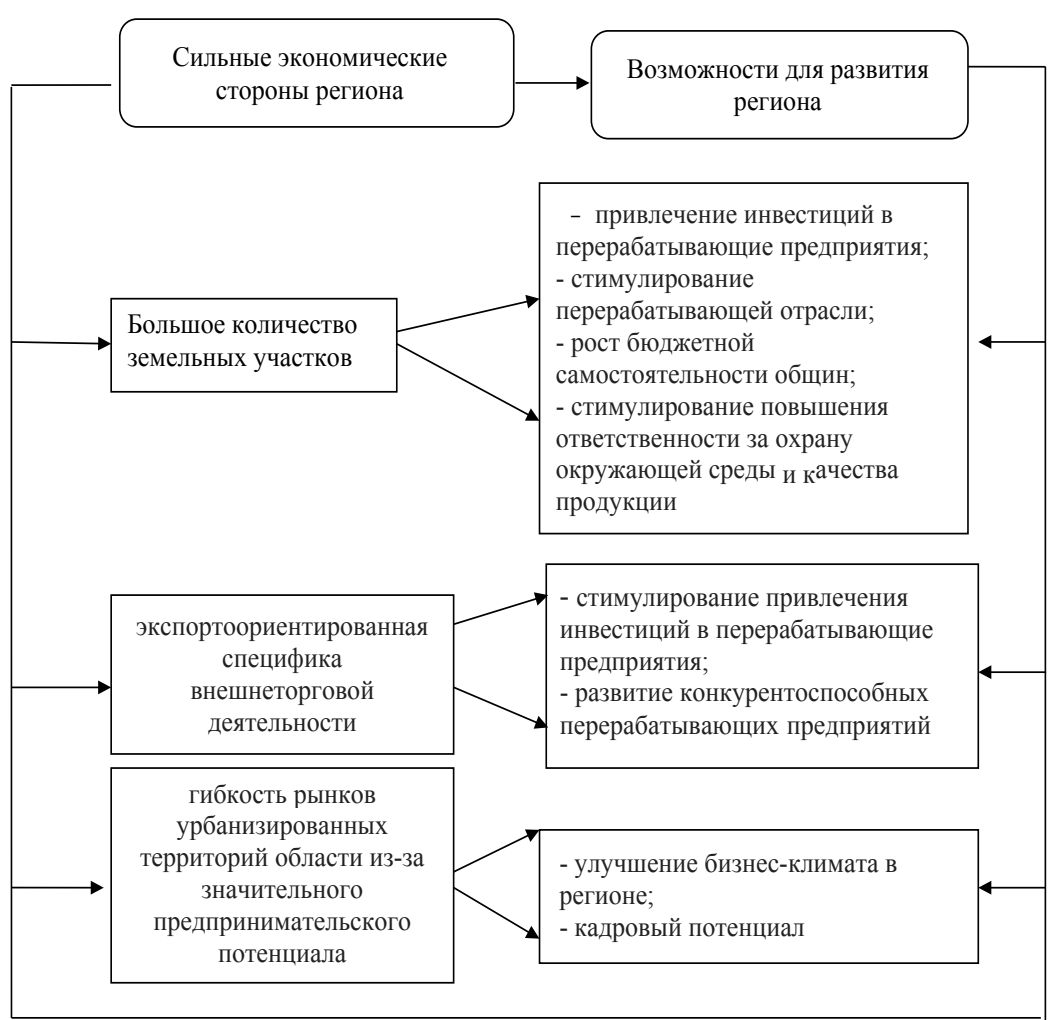

Рис. 3. Можиивости Аля развития перерабатывающих преАприятий бцагодаря симьным экономическим сторонам региона

Источник: разработано автором ние технического перевооружения.

Херсонская область характеризуется Аифференцированным промышменным потенциалом, стимулирует развитие размичных отраслей переработки на ее территории, развивает внешнеэкономические связи, в том числе со странами Европейского Союза, увемичивает мировой спрос на готовую продукцию перерабатывающих преАприятий. В области имеются высшие учебные заведения и центры переподготовки кадров, которые обеспечат перерабатывающим предприятиям высококвалифицированных сотруАников в сфере переработки и эффективный менеАжмент.

Существование значительного количества земельных участков и разнообразие природных ресурсов способствует росту бюАжетной самостоятемьности общин, так как территориальная община может испомьзовать природные ресурсы территории Амя своего экономического развития. Так как Херсонская обмасть явмяется аграрной, то многообразие природных ресурсов и значительное количество земемьных участков будет стимумировать развитие перерабатывающих преАприятий, в том числе пищевых, преАприятий мегкой промышиенности. То есть, сильные стороны региона, гАе находится перерабатывающее преАприятие, стимулирует развитие такого преАприятия.

Осуществляя Аеятельность и развиваясь, перерабатывающее преАприятие способствует экономической независимости и эффективному развитию территориамьной общины, на территории которой оно находится, способствует благоустройству насемения общины, принимает участие в решении ее социальных проблем, каАровых вопросов, вопросов привлечения инвесторов и спонсоров. Благодаря улучшению инвестиционного кмимата территориальная община может развиваться, повышать спрос и покупательную способность населения.

На ряду с существованием сильных сторон Херсонская обмасть имеет также и слабые стороны своего развития. Основными проблемными сторонами Херсонской обмасти, которые могут помешать развитию перерабаты- 
вающих преАприятий, явцяются: отсутствие системы сбора и утилизации твердых бытовых отходов, высокий уровень физического износа и энергоемкость большинства преАприятий области, низкий уровень внеАрения ресурсосберегающих технологий, ограниченность трудоустройства в сельской местности, недостаточное количество очистных сооружений и низкий уровень Аействующих, слабо развита инфраструктура подАержки бизнеса и привлечения инвестиций, неАостаточная финансово-кредитная поААержка перерабатывающих предприятий области из бюАжетов всех уровней.

Решению проблемных вопросов экономики региона может способствовать организация новых и развитие Аействующих перерабатывающих предприятий. Так, проблему ограниченности трудоустройства в сельской местности и незначительное количество рабочих мест, которые привлекают молодежь, может решить организация перерабатывающих предприятий в сельской местности. Такая местность, исходя из симьных сторон Херсонской области, имеет большой ресурсный потенциал, земли пригоАны Аля выращивания агропромышиенной продукции, которая явмяется сырьем Аля перерабатывающих преАприятий. Такие преАприятия усилят территориальные общины населением трудоспособного возраста.

То есть, мы можем набцюдать взаимную отАачу и взаимную зависимость перерабатывающих преАприятий и региона, в том числе территориальной общины. Встречным Авижением со стороны территориальной общины региона будет предоставление организационной, экономической и Аругих возможных форм поААержки перерабатывающим предприятиям.

Принимая во внимание выгодное территориацьно-географическое положение региона (выхоА области в черноморско-азовского побережья и значительный транспортный потенциац) - нахожАение преАприятия в сельской местности не созАаст проблем при доставке продуктов переработки. вана на Авух подходах: на этапе организации преАприятия и на этапе развития преАприятия.

На этапе организации преАприятия, первый критерий на который опирается основатель перерабатывающего преАприятия - это инвестиционная привцекательность региона. Эта категория, в первую очереАь, включает в себя - территориально-географические характеристики региона: наличие и плодородие земельных ресурсов Аля сырья переработки, наличие воАоемов Аля построения очистных сооружений и технического использования преАприятием, выхоА К морским, речным портам, разветвценная транспортная система. Важным фактором на сегодняшний день явмяется существование территориальных общин в Аанном регионе, поскольку они влияют на утверждение стратегий развития территории, приоритетные экономические и промышленные направления.

Важным фактором Аля основания перерабатывающего преАприятия на опреАеленной территории являются социальные вопросы, Аемографическая ситуация региона, наличие каАрового потенциала, существование центров образования - подготовки и переподготовки, Аля специалистов профиля переработки. Также важна политическая стабильность, отсутствие военной угрозы, уровень преступности и покупательная способность населения (рис. 4).

Стимулом организации перерабатывающего преАприятия на Аанной территории явцяются условия Аеятельности, которые и являются сильными сторонами определенного региона.

На этапе развития предприятия критерием выступает соответствие стратегии регионального развития. Аанная стратегия - составная часть стратегии развития государства и поэтому должна соответствовать ее основным направлениям и целям. Большую роль зАесь играют территориальные общины как учреАители и практики стратегий. Если Аеятельность преАприятия соответствует основным направлениям развития, определенных стратегиями развития, то перерабатывающее преАприятие Аанного региона получит поА-

\section{4. Модель управмения перерабатывающими преАприятиями}

Исходя из провеАенного анахиза, мы преАлагаем территориально - ориентированную модель управления перерабатывающим преАприятием. Ее использование направлено на взаимную зависимость и взаимной отАачу территории, на которой находится перерабатывающее преАприятие и самого преАприятия. Используя сильные стороны региона, преАприятие развивается и наоборот: преАприятие предоставляет стимулы Аля развития Аанного региона. Такая модемь осно-

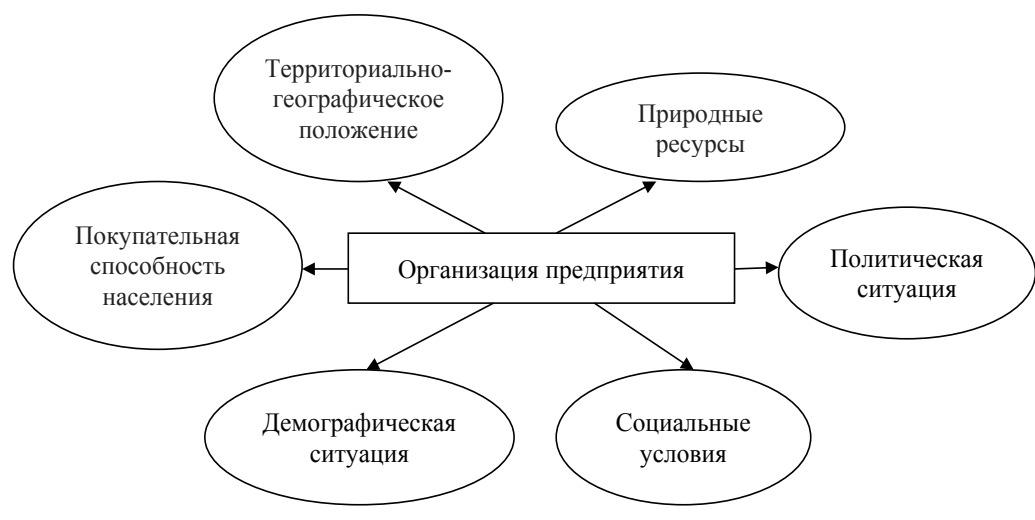

Рис. 4. Территориально-ориентированное управцение перерабатывающим преАприятием на этапе организации

Источник: разработано автором 
Аержку: государственную, регионацьную, территориамьную.

Это и будет стимулом Аля развития перерабатывающего преАприятия на Аанной территории.

\section{5. ВЫВОАЫ}

Территориально-ориентированное управление перерабатывающим преАприятием - это эффективная модель организации и управления. Такая модель охватывает все сферы влияния на развитие предприятия. Она основана на взаимосвязи территории и перерабатывающего предприятия и обеспечивает получение государственной подАержки в рамках утвержАенной стратегии развития определенной территории.
В предлагаемой модеми, мы набцюдаем, что на первом этапе - организации преАприятия, его основатель ориентируется на территориально привлекательное расположение предприятия. На втором этапе - развитие, преАприятие развиваясь в соответствии со стратегий развития регионов и госуАарства, имеет возможность получить государственную поААержку, и получив ее, положительно повлиять на территорию, уменьшая ее негативные стороны, развивает ее.

Наши дальнейшие исследования будут направлены на анализ внеАрения территориально-ориентированной модели управмения перерабатывающими предприятиями и поиск новых эффективных модемей управления ими.

\section{References:}

Bugayenko, N. (2010). Sovremennyye tendentsii razvitiya sistemy gosudarstvennoy pomoshchi v YES. Statistika Ukrainy, 1, 92-98.

Danieli, P. (2012). Sostoyaniye razvitiya predpriyatiy pererabatyvayushchey otrasli v regional'nom aspekte. Ekonomika promyshlennosti. 3-4, 22-28.

Dogovor ob osnovanii Yevropeyskogo Soobshchestva: zakonodatel'stvo Ukrainy. Mezhdunarodnyye dokumenty (2005) from: http: //zakon1.rada.gov.ua/cgi-bin/laws/main.cgi?nreg=994_017

Ukaz Prezidenta Ukrainy «O strategii ustoychivogo razvitiya $\ll$ Ukraina-2020» (2015) from: http://zakon3.rada.gov.ua/laws/show/5/2015

Strategiya razvitiya Khersonskoy oblasti na period do 2020 goda (2015) from: http://khoda.gov.ua/strategiyarozvitku-2020

Investytsiynyy potentsial Khersons'koyi oblasti (2017) from: http://khoda.gov.ua/departamentzovnishnoekonomichno\%25d1\%2597-diyalnosti-turizmu-ta-kurortiv

\section{Надежда ОНИКИЕНКО}

\section{ТЕРРИТОРИАЛЬНО-ОРИЕНТИРОВАННАЯ МОДЕЛЬ УПРАВЛЕНИЯ ПЕРЕРАБАТЫВАЮЩИМИ ПРЕДПРИЯТИЯМИ УКРАИНЫ}

Аннотация. Предметом исследования данной статьи являются перерабатывающие предприятия Украины. В период политической и экономической нестабильности, когда осуществляется государственная децентрализация и территориальные общины получают большие полномочия и ресурсы, вопрос построения модели управления предприятиями приобретает все большую актуальность. Целью статьи является разработка эффективной модели управления перерабатывающими предприятиями соответствующей целевому направлению развития государства. Методика. В процессе анализа было установлено, что эффективная модель управления перерабатывающими предприятиями должна соответствовать стратегиям развитиями государства и отдельного региона. Эти стратегии взаимосвязаны и предусматривают комплексный системный подход. Исследование основано на анализе сильных и слабых сторон региона: территориально-географических, экономических, промышленных. Исходя из анализа сильных сторон области, были определены возможности для эффективного развития перерабатывающих предприятий на данной территории и разработана модель территориально-ориентированного управления предприятиями. Модель основывается на принципах экономического и политического развития региона, с помощью которой реализуются его возможности. Выводы исследования. Территориально-ориентированное управление перерабатывающим предприятием - это эффективная модель организации и управления. Такая модель охватывает все сферы влияния на развитие предприятия. Она основана на взаимосвязи территории и перерабатывающего предприятия и обеспечивает получение государственной поддержки в рамках утвержденной стратегии развития определенной территории. В предлагаемой модели, мы наблюдаем, что на первом этапе - организации предприятия, его основатель ориентируется на территориально привлекательное расположение предприятия. На втором этапе - развитие, предприятие, развиваясь в соответствии со стратегий развития регионов и государства, имеет возможность получить государственную поддержку и положительно повлияет на территорию, уменьшая ее негативные стороны, развивает ее. 